\title{
Conversando sobre a prevenção do HIV/AIDS com homens jovens usuários de crack
}

\author{
Talking about the prevention of HIVIAIDS with young men \\ crack users
}

\author{
Agnes Caroline Souza Pinto ${ }^{1}$ - Adna de Araújo Silva ${ }^{\bullet}$ Adriana Gomes Nogueira Ferreira ${ }^{3}$ Álissan Karine Lima Martins ${ }^{4}$ \\ - Patrícia Neyva da Costa Pinheiro ${ }^{5}$
}

\begin{abstract}
RESUMO
Objetiva-se relatar a intervenção educativa com jovens usuários de crack visando à prevenção do HIV/Aids, utilizando a metodologia de Círculo de Cultura. Pesquisa-ação realizada em 2012 com dez jovens usuários de crack atendidos em uma comunidade terapêutica de Fortaleza-CE. A coleta de dados incluiu: observação participante com diário de campo, registro fotográfico e filmagem. A análise e interpretação dos resultados privilegiaram a discussão conforme experiência vivida pelo grupo. Nos resultados, foi possível perceber que na sua maioria dos casos, os jovens não associaram o uso de drogas à contaminação pelo HIV, enfocando que apenas o preservativo deve ser utilizado para a prevenção da doença, demonstrando pouco conhecimento em relação à temática. Concluí-se que a enfermagem deve pensar na realização de pesquisas com participação ativa dos sujeitos, utilizando estratégias pedagógicas dialógicas, como a de Paulo Freire, para favorecer uma reflexão crítica sobre o tema das drogas e sua estreita relação com a vulnerabilidade dos jovens ao HIV/Aids.
\end{abstract}

Palavras-chave: Adolescente; Educação em Saúde; Síndrome da Imunodeficiência Adquirida; Crack.

\begin{abstract}
The aim is to report educational intervention with young crack users in order to prevent HIV / AIDS, using the methodology of Culture Circle. It is action research, carried out with ten young crack users in a therapeutic community between May and July 2012. Data collection included: participant observation diary, photographic recording and filming. The analysis and interpretation of results favored the discussion as lived experience of the group. The results provided the evidence of the majority of young people do not associate the use of drugs to HIV infection, focusing on only the condom should be used for the prevention of disease, showing little knowledge in relation to the theme. It concludes that nursing should consider in conducting research with active participation of the subjects, using dialogic teaching strategies, such as Paulo Freire, to promote a critical reflection on the subject of drugs and its close relationship with young people's vulnerability to HIV/AIDS.
\end{abstract}

Keywords: Adolescent; Health Education; Acquired Immunodeficiency Syndrome; Crack.

${ }^{1}$ Extraído da dissertação "Círculo de Cultura com jovens usuários de cocaína/crack visando a prevenção do HIV/AIDS", apresentada ao Programa de Pós-Graduação em Enfermagem da Universidade Federal do Ceará (UFC), em 2013.

${ }^{1}$ Enfermeira. Doutoranda do Programa de Pós-Graduação em Enfermagem da Universidade Federal do Ceará (UFC). Enfermeira do Instituto Federal de Educação, Ciência e Tecnologia do Ceará (IFCE). Fortaleza, CE, Brasil. E-mail: agnespinto@hotmail.com.

Endereço para correspondência: Rua Alexandre Baraúna, 1115, Rodolfo Teófilo; CEP 60.430-160. Fortaleza, CE. Telefone: (85) 3878 6326.

${ }^{2}$ Enfermeira. Doutoranda do Programa de Pós-Graduação em Enfermagem da Universidade Federal do Ceará/UFC. Enfermeira do Hospital de Messejana Dr. Carlos Alberto Studart Gomes. Fortaleza, CE, Brasil. E-mail: adnaaraujo@yahoo.com.br

${ }^{3}$ Enfermeira. Doutora em Enfermagem pela Universidade Federal do Ceará (UFC). Docente do curso de graduação em Enfermagem da Universidade Federal do Maranhão (UFMA). Imperatriz, MA, Brasil. E-mail: adrianagn2@hotmail.com

${ }^{4}$ Enfermeira. Doutora em Enfermagem pela Universidade Federal do Ceará (UFC). Docente do curso de graduação em Enfermagem da Universidade Regional do Cariri (URCA).

Crato, CE, Brasil. E-mail: alissankarine@gmail.com

${ }^{5}$ Enfermeira.Pós-Doutora em Global Community Health and Behavioral Sciences. Docente da Universidade Federal do Ceará (UFC).Fortaleza, CE, Brasil. E-mail: neyva.pinheiro@yahoo.com.br 


\section{INTRODUÇÃO}

Cronologicamente, a Organização das Nações Unidas (ONU) delimita o jovem como o indivíduo com idade situada entre 15 e 24 anos, parâmetro que foi estabelecido em 1985, Ano Internacional da Juventude, pela Assembleia Geral das Nações Unidas ${ }^{1}$. Para a Secretaria Nacional de Juventude do Brasil, os limites da faixa etária para os jovens são entre 15 a 29 anos, de acordo com o Estatuto da Juventude (Lei 12.852/13)2.

A juventude é o período de transição compreendido entre a adolescência e a fase adulta, caracterizada pelos impulsos do desenvolvimento físico, mental, emocional, sexual e social. Esta fase é marcada pela busca de identidade, pela curiosidade, onipotência e contestação, o que desperta uma sensação de invulnerabilidade. Estes aspectos, associados a pouca experiência e a falta de informação adequada frente a um sistema educacional pouco estruturado e desestimulante além da baixa qualidade de serviços de saúde fazem com que estes se tornem altamente vulneráveis ${ }^{3}$.

Esta vulnerabilidade evidencia-se quando muitos jovens mergulham no presente sem estabelecer perspectivas para o futuro através de um projeto de vida 4 . Estudo realizado com jovens escolares apontou que estes indivíduos compreendem o risco como algo característico desta fase, marcada pelos processos de contestação da ordem, estabelecimento de outros tipos de relações e tentativas de romper com o ciclo reprodutivo da pobreza e da violação dos direitos, o que culmina na incidência dos riscos e da vulnerabilidade na saúde ${ }^{3}$.

Dentre estes riscos, o uso de drogas lícitas e ilícitas está incluso como uma importante questão em saúde pública. 0 álcool, tabaco, cocaína, crack e maconha são as principais substâncias utilizadas pelos jovens, fazendo parte dos territórios de existência e se caracterizando como realidades comuns, percebidas algumas vezes como reflexo da "falta de governantes" ou da "falta de condições (socioeconômicas)"

Sobre a experiência da sexualidade, esta traduz as potencialidades do próprio existir especialmente se colocada no campo das descobertas, experimentações e vivência da liberdade, servindo também de aporte à construção da capacidade de tomada de decisões, exercida de forma singular e com a urgência própria dos adolescentes $^{3}$. Nesse campo, a busca de aventura e prazer não encontra barreiras para sua realização pelos jovens, tornando fundamental intervir de maneira dialógica sobre o método de prevenção das doenças sexualmente transmissíveis (DST) para gerar a conscientização ${ }^{5}$.

Desta forma o comportamento sexual de usuários de crack pode ser considerada fator de risco para a infecção pelo HIV, pois apesar de terem acesso a informações sobre HIV/Aids, não mudam os comportamentos que os expõem a uma possível infecção ${ }^{6}$.

Apesar de no Brasil e em outros países do mundo os jovens serem expostos a muitas informações em massa, essas medidas se esvaziam quando são destituídas da singularidade cultural, religiosa e social de cada sujeito, propiciando apenas um conhecimento genérico sobre determinados assuntos, evidenciadas pelos indicadores de saúde deste segmento geracional ${ }^{4}$. Assim é importante conhecer os comportamentos dos usuários de crack, não só porque o consumo tem crescido, mas também porque apresentam alguns comportamentos, especialmente relacionados à atividade sexual, que podem direcionar para uma nova orientação na prevenção do HIV/Aids e outras DST6.

Neste contexto, cabe aos profissionais de saúde utilizarem como estratégia a educação em saúde para possibilitar a formação e desenvolvimento de novos comportamentos e o empoderamento, de modo a se tornarem sujeitos mais críticos e conscientes. Para isso, é necessário compreender como os jovens percebem sua realidade, a partir de uma escuta sensível ao pensar, às percepções e necessidades deste público, de modo a estabelecer possibilidades reais e contextuais do e para o mundo, sobretudo no que diz respeito às políticas e ações em saúde ${ }^{7}$.

A enfermagem exerce função educativa na promoção da saúde e prevenção de doenças e agravos, no qual - cuidado ganha espaço nas intervenções sociais, ambientais e educacionais. Diante do exposto, surgiu o seguinte questionamento: Quais estratégias educativas a enfermagem pode desenvolver para dialogar com jovens usuários de crack sobre a prevenção do HIV/Aids?

Dessa forma, o presente artigo teve como objetivo relatar intervenção educativa com jovens usuários de crack com vista a prevenção do HIV/Aids, utilizando a metodologia de Círculo de Cultura.

\section{MÉTODO}

Estudo exploratório e descritivo, utilizando-se a pesquisa-ação, fundamentada na metodologia de Círculo de Cultura ${ }^{8}$. Participaram dez jovens usuários de crack atendidos em comunidade terapêutica de referência em Fortaleza-CE e para a seleção dos sujeitos utilizou-se os critérios de inclusão: usuários das unidades de tratamento para dependentes químicos e que referiram ter feito uso de crack. Adotou-se como faixa etária de jovens a indicação do Estatuto da Juventude (Lei 12.852/13), que aponta tratarse de indivíduo entre 15 e 29 anos de idade, visto que o núcleo de internamento é exclusivo para homens maiores de 16 anos $^{2}$.

As informações foram produzidas de maio a julho de 2012 por meio da observação participante, diário de campo, filmagem de imagem por vídeo e as etapas do Círculo de Cultura. Os Círculos de Cultura aplicados seguiram as fases do método teórico de Paulo Freire, adaptando-os ao alcance dos objetivos propostos: descoberta do universo vocabular, dinâmica de sensibilização e acolhimento, construção de situações para a problematização (trabalhar 
a(s) questão(ões) norteadora(as)), fundamentação teóricocientífica estimulando a reflexão crítica, síntese do que foi vivenciado e avaliação?.

Cada Círculo teve a duração de duas horas e meia e ocorreu mediante três momentos: No acolhimento, realizaramse atividades com jogos, desenhos, colagens e exposição de vídeos, para que possibilitassem aos participantes falarem sobre as expectativas e conhecimentos prévios. Para a problematização, utilizaram-se técnicas grupais como a modelagem, jogos, paródias, textos e vídeos com questões que favoreceram a reflexão crítica da realidade. $\mathrm{Na}$ avaliação, realizou-se a síntese do que foi vivenciado em cada Círculo, por meio da autoavaliação, em que foi apreciada participação, interesse, motivação e apreensão do conteúdo pelo grupo, assim como a atuação da facilitadora.

Para análise das informações, recorreu-se à triangulação de dados, cujo processo refere-se à convergência ou corroboração dos dados obtidos pelos diferentes métodos e técnicas utilizados nas pesquisas visando à qualidade, profundidade e validade da análise qualitativa ${ }^{10}$.

Propôs-se, ainda, ao pesquisador uma análise crítica e ampla na interpretação do material empírico extraído. Este processo ocorreu mediante descrição minuciosa dos eventos ocorridos nos Círculos de Cultura, dos depoimentos dos sujeitos, observações, participações nas discussões, experiência das atividades realizadas em grupo para problematização da vulnerabilidade ao HIV/Aids, e o significado da vivência educativa no Círculo de Cultura pelos envolvidos.

A interpretação dos resultados foi avaliada pelo grupo, pela experiência do pesquisador e pelo diálogo com as fundamentações teóricas do método de Paulo Freire consideradas relevantes e enriquecedoras ao estudo crítico do discurso popular 9 .

0 estudo obedeceu aos aspectos éticos e legais da pesquisa envolvendo seres humanos ${ }^{11}$, sendo aprovado pelo Comitê de Ética em Pesquisa da Universidade Federal do Ceará (COMEPE), Protocolo No 303/11. O Termo de Consentimento Livre e Esclarecido (TCLE) foi assinado pelos jovens e seus respectivos responsáveis. Nesse sentido, os jovens foram identificados pelo termo usuário (U), seguido de número de ordem das falas.

\section{RESULTADOS E DISCUSSÃO}

A aproximação da pesquisadora aos jovens ocorreu por meio de quatro visitas à comunidade terapêutica, o que possibilitou a imersão no cenário de convívio dos jovens e a participação nas atividades realizadas pela instituição. Ao final da última visita, foram questionados os motivos que os levaram a usar drogas, se eles sabiam algo sobre o HIV/ Aids, e se achavam vulneráveis à essa doença enquanto usuários de drogas.

As visitas foram primordiais haja vista a necessidade de conduzir prática educativa em que o aprender se torne um ato baseado na situação real vivida pelo grupo de jovens, bem como resultado de uma aproximação crítica dessa realidade.

Os dez jovens eram do sexo masculino e na faixa de 18 a 24 anos de idade. Quanto ao nível de escolaridade, um tinha o fundamental incompleto, dois completaram o ensino fundamental, cinco adolescentes tinham o ensino médio incompleto e apenas dois cursaram o ensino médio completo. Quanto ao estado civil, dois eram casados, dois conviviam conjugalmente, e seis solteiros. Em sua maioria os adolescentes tinham algum tipo de emprego informal e estavam afastados para fazer o tratamento da dependência do crack, pois era impossível se dedicar ao trabalho sob o efeito da droga.

\section{$1^{\circ}$ Círculo de Cultura - A relação da Aids com as drogas}

O início do Círculo foi marcado por conversas informais, incluindo perguntas sobre o cotidiano e rotina no serviço, o tratamento além dos sentimentos e expectativas quanto aos encontros. Após a conversa introdutória, iniciou-se o acolhimento com uma técnica que teve por finalidade mostrar aos participantes que todas as pessoas sexualmente ativas estão vulneráveis ao contágio de DST/ Aids além de demonstrar a rapidez que a Aids e as DST podem ser propagadas, e como detê-las.

A técnica consistiu em que cada pessoa recebia uma tira de papel e a instrução de que teria de recolher o máximo de assinaturas em 20 segundos. Em um dos papéis tinha um pequeno $\mathrm{H}$ e em outro um $\mathrm{C}$, e, no entanto, ninguém foi avisado previamente disto. Em uma única tira de papel havia a seguinte informação NÃO RECOLHA E NEM DÊ ASSINATURA PARA NINGUÉM. Quando todos terminaram de pegar as assinaturas, a facilitadora pediu para que procurassem a pessoa que tinha um $\mathrm{H}$ em seu papel; este era o portador do HIV. A partir daí se formou a cadeia de contaminação. Só não se contaminou quem estava usando a camisinha representada pelo $C$, e aquela que tinha o papel de instrução de não recolher assinatura.

A vivência possibilitou alguns pontos de reflexão entre o grupo:

- Como se sentiu a pessoa "H"?

Eu me senti triste, não gostei de ser o HIV não (U3).

- Como se sentiu a pessoa "C"?

Eu me senti, uma coisa assim, extraordinariamente incrivel (U5).

- Como se sentiu a pessoa que recebeu a tarjeta NÃO RECOLHA E NEM DÊ ASSINATURA PARA NINGUÉM?

Normal, eu não achei ruim em não participar, eu achei foi bom (U6).

Não participar de uma atividade da qual todos participam foi indiferente para U6. Tal achado vai de 
encontro à tendência grupal que acontece nessa fase da vida. A adolescência é um período de intensa sociabilidade, em que as normas vigentes no grupo de pares e as expectativas sociais têm uma importância acrescida, sendo comum o adolescente imitar os pares, adotando hábitos e atitudes semelhantes ao seu grupo etário ${ }^{12}$.

- O que sentiram ao descobrir que podiam ter sido contaminados?

Eu me senti muito feliz em não ter assinado na tarjeta de U3, me senti aliviado (U7).

Eu estou refletindo até agora que eu me contaminei rapidinho, confiei no amigo e assinei mesmo, da próxima vez vou ter mais cuidado (U8).

Ao continuarmos a reflexão, foi solicitado aos participantes que pensassem em um conselho que daria para um amigo usuário de drogas para ele se prevenir do HIV. Cada participante pegou a tarjeta com um chocolate dentro, que estava embaixo de cada cadeira. Enquanto degustavam o chocolate, foi dado um tempo de 10 minutos, para que pensassem e escrevessem o conselho.

U4 pediu para começar: eu diria para o meu amigo se prevenir; U5 continuou: eu diria para ele tomar cuidado com essas mulheres da vida, e que ele se protegesse sempre usando camisinha; U3 prosseguiu: eu diria para ele parar de usar droga, e se fosse ter relação com alguém ser sempre com camisinha; U7 continuou: eu diria para ele ir para a igreja. Nesse momento todos riram e ficaram brincando com U7 dizendo: valeu irmão U7. U6, U8 e U9 deram continuidade: eu diria para ele não fazer sexo sem preservativo.

Os conselhos giraram em torno do uso do preservativo em todas as relações sexuais, e apenas um participante referiu que o amigo deveria parar de usar droga. Mesmo com o conteúdo já discutido, mas não aprofundado, percebeu-se que para eles a transmissão do vírus somente estava relacionada à via sexual. Dado semelhante foi encontrado em pesquisa realizada com prostitutas sobre o comportamento diante das DST, em que estas, em sua maioria, referiram que a prevenção se dá por meio do uso do preservativo, mesmo diante dos relatos de uso frequente de drogas lícitas e ilícitas por elas ${ }^{13}$.

Para este momento de problematização, utilizouse o processo de modelagem, para que os participantes fizessem esculturas baseadas no seguinte questionamento: o que você entende sobre as DST/Aids e sua relação com as drogas?

Após pensarem por alguns minutos, começaram a modelar. Assim, foi possível explorar a criatividade dos participantes do grupo na produção de material lúdico, possibilitando no conhecimento da subjetividade estabelecer relação direta com a realidade. Os resultados foram:

Um rapaz e uma moça, que estão tendo relação sexual, e depois eles irão usar droga. Existe na escultura também, um canudo, e um prato com o "pó" dentro, o que exemplifica o uso aspirado da cocaína (U3).

U5 modelou a relação sexual entre o casal que estava cercado pela dúvida, se usava ou não o preservativo, e acrescentou escrevendo na sua escultura:

Esta dúvida de usar ou não a camisinha, é que o sujeito se torna vulnerável às DST (U5).

O rapaz fumando um "paraguaio" (baseado) e a mulher sem usar droga. Mas ela "sai" com ele e pega doenças transmitidas, porque não usam camisinha (U4).

U6 também modelou um casal, em que o homem estava com um cachimbo na boca e a mulher estava chamando para fazer sexo com uma bolsinha na mão. Ele ainda escreveu na escultura: drogas e DST sempre andam juntas.

U7 modelou um rapaz que chamou de Chico:

Ele já está contaminado pelo HIV, por isso que está fumando esse cachimbo grande e preto (U7).

Ao observar as falas, foi percebido que apenas um participante falou da relação entre as DST/Aids e as drogas. Porém, a maioria falou de forma desarticulada, ora somente da droga e outra vez das DST, esta sempre enfocando o uso do preservativo, demonstrando não conhecerem como as drogas influenciam na infecção pelo HIV.

Estudo com meninos de rua evidenciou que o fato de estar na rua significava vivenciar várias situações de medo constantemente, isto devido às várias formas de violência e à drogadição. Estas formas são acompanhadas pelas relações sexuais com múltiplos parceiros e desprotegidas, levando a maior risco de infecção pelas DST/Aids. Para eles, o HIV é somente mais um dos riscos que eles têm que enfrentar diariamente, e que a preocupação da doença ocorre quando conhecem que alguém do grupo está com a doença, chegando a excluir essa pessoa como medida de proteção. Quando estavam sob o efeito de drogas, relataram ser incapazes de assumirem comportamento sexual responsável, assim como os jovens do nosso estudo ${ }^{14}$

Ao final da atividade, realizou-se avaliação oral e alguns falaram o que tinha achado do grupo:

Foi muito produtivo o dia de hoje, e ainda Ihe digo mais, nós estamos sendo os internos mais felizes de 2012 (U5).

Eu gostei muito porque a senhora traz coisa diferente para a gente aprender (U8).

A gente fica ansioso por cada encontro, porque a gente sabe aprende algo novo e compartilha com os colegas os mesmos problemas (U4).

Observou-se pelas falas dos jovens, a ansiedade e a alegria em receber as pesquisadoras a cada encontro, e que para eles estava sendo divertido e interessante aprender assuntos novos como as DSTs /Aids. 


\section{$2^{\circ}$ Círculo de Cultura - Conversando sério sobre a prevenção do HIV/AIDS}

Para abordar sobre a prevenção do HIV/Aids, é necessário conhecimento acerca do assunto. No Círculo anterior, ficou evidenciado o pouco conhecimento do grupo com relação ao tema, o que motivou o planejamento do segundo momento a partir do aprofundamento da doença. Neste dia, a sala estava bastante colorida, com dois álbuns seriado, cartazes, próteses penianas, material educativo para entregar a cada participante, preservativos e multimídia para apresentação de vídeo.

No primeiro momento, realizou-se técnica intitulada: o que sabemos sobre o HIV/Aids? que objetivou levantar informações sobre Aids conhecidas pelos jovens e informálos corretamente sobre o que é Aids, formas de transmissão e como se prevenir. A facilitadora pediu que os participantes formassem dois grupos; a seguir, distribuíram as 30 tiras de cartolina já preenchidas com as frases, embaralhadas, e colocou o papel madeira no quadro para cada grupo. Estas tiras deveriam ser organizadas de acordo com as seguintes divisões: 1 (Pode-se pegar Aids), 2 (Formas de prevenção), 3 (Não se pega Aids) e assim construiu-se um painel de três partes. Quando os grupos terminaram, a facilitadora pediu para eles formarem um círculo, para que juntos fosse realizada a leitura quadro por quadro, corrigindo os erros e colando o que estivesse errado na coluna certa.

$\mathrm{Na}$ proporção que se liam os quadros, aconteciam os esclarecimentos das dúvidas e erros. No quadro "Pode-se pegar Aids", o Grupo 1 acertou todos os itens, o Grupo 2, cometeu os seguintes erros, colocando tarjetas de outros quadros como: cuidando de pessoas contaminadas (não se pega Aids); tomar injeções e vacinas, utilizando-se sempre de agulhas e seringas descartáveis (formas de prevenção); exigir teste no sangue doado para transfusões (formas de prevenção); na gravidez, parto e amamentação (pode-se pegar Aids), eles colocaram no quadro formas de prevenção.

Nesse primeiro momento de leitura dos quadros, evidenciou-se que apesar dos diversos espaços de informação como mídia, escola, internet, pais e amigos, alguns desses jovens ainda não tinham familiaridade com o tema, com dúvidas sobre questões difundidas pelos meios de comunicação, mas que não chegavam até eles.

Pesquisa realizada com o objetivo de verificar o conhecimento de adolescentes sobre DST/Aids, encontrou que o tema não é totalmente desconhecido pelos adolescentes do estudo. $\mathrm{O}$ conhecimento e desconhecimento se mesclaram nas questões analisadas, como por exemplo, em relação à cura das DST, onde $57 \%$ do grupo feminino e $71 \%$ do grupo masculino referiram não ter conhecimento do assunto ${ }^{15}$.

Algumas perguntas foram emergindo ao passo que se lia esse primeiro quadro: o sexo anal é mais perigoso do que o sexo vaginal? Quer dizer que no leite materno tem o vírus do HIV, então a mãe não pode amamentar nenhuma vez? O sexo oral é mais difícil da pessoa pegar o HIV do que o sexo vaginal? Se a pessoa tiver só uma relação vaginal com uma mulher HIV, ele já pega também? Esses questionamentos demonstram o quanto a problematização auxilia na descodificação do tema pelo grupo, com a colaboração da facilitadora.

Seguindo a ordem em que a leitura foi realizada, o quadro "Formas de prevenção" foi o segundo ser debatido. Neste quadro, discutiu-se sobre como é feita atualmente a doação de sangue. Esse assunto foi levantado por U5, que ao ir ao banco de sangue fazer a doação, foi reprovado durante a entrevista, visto ser usuário de drogas.

No último quadro "Não se pega Aids" foram colocadas 17 tarjetas, visto que muitas coisas que se sabem sobre a Aids é mito. Neste aspecto, inseriram-se os mais diversos assuntos para serem analisados pelos jovens. 0 beijo foi algo questionado, que dependendo do beijo, se existia ferida na boca, o outro poderia pegar; a questão do inseto não transmitir o vírus foi bastante conversada com eles. O Grupo 1 foi o vitorioso, mas entregaram-se a todos os participantes um livrinho do Ministério da Saúde sobre direitos sexuais, direitos reprodutivos e métodos anticoncepcionais.

Para complementar esse primeiro momento, exibiu-se um vídeo educativo de cinco minutos sobre a prevenção e a transmissão da Aids a partir da solicitação deles. Segundo os jovens, a imagem causa maior impacto na mente das pessoas do que somente o discurso, e os ajudam na memorização que estava prejudicada devido ao consumo de crack. Com efeito, os vídeos surgiram como relevantes instrumentos para subsidiar a Educação em Saúde e contribuir para prevenção de DST/HIV/Aids ${ }^{16}$.

No segundo momento, para promover o conhecimento do corpo e abordar sobre a prevenção das DST/Aids de forma lúdica, levou-se um jogo bastante utilizado no Projeto Aids: Educação e Prevenção, para estimular o autocuidado em relação à saúde sexual e à saúde reprodutiva. 0 jogo segue o estilo dominó e no encontro se dividiu o grupo em duas equipes onde cada uma ficou com a metade das peças do dominó, ou seja, 15 peças. Cada peça do dominó tinha uma DST que ia encaixando até terminar.

O jogo se inicia pela peça símbolo da Aids, e daí segue pelo significado deste símbolo, depois pela definição do que é prevenção, adolescência, passando pelos órgãos masculinos: testículo e espermatozoide, depois pelos órgãos femininos: útero, ovários e óvulos, período fértil, definição e tipo de DST, sintomas, doenças oportunistas, prevenção e tratamento.

Durante o jogo, explicou-se, com uma prótese feminina, onde era o clitóris, a uretra e a vagina da mulher, motivo de bastante curiosidade por parte dos jovens, principalmente aqueles que não tinham tido a oportunidade de ter relação sexual ainda. Mostrou-se, também, onde é produzido o espermatozoide e o caminho que ele percorre até sair pela uretra. $O$ período fértil da mulher foi outra questão que eles fizeram muito empenho em aprender. 
À medida que se discutia e formava o dominó, completava-se as informações com o uso de projeção de apresentação informativo sobre as DST/HIV/Aids, com questionamentos sobre temas já debatidos. A ideia de trazer a apresentação com ênfase em imagens foi solicitada por eles, visto que estas mostram realmente como se apresentam cada doença e facilita o aprendizado. Segundo eles, a imagem é importante porque é algo real, que fica gravado na mente deles, e faz com que fiquem mais preocupados em não contrair nenhuma das doenças apresentadas.

Estudo com adolescentes fez a utilização deste mesmo jogo educativo como estratégia educacional em saúde para a prevenção de DST/Aids, experiência exitosa por haver favorecido executar-se o fenômeno educativo mediante o consórcio entre informação, debate, reflexão, influência recíproca e participação grupa ${ }^{17}$.

$\mathrm{Na}$ avaliação do Círculo, foi possível perceber a mudança na visão acerca das DST e da Aids, conforme relatos:

Agora quando aparecer qualquer coisa em mim, principalmente na região genital, eu vou ao posto de saúde, porque a maioria dessas doenças têm tratamento e ainda é de graça (U5).

Se eu souber que um amigo meu tem o HIV, não vou ter mais medo dele, vou é ajudá-lo para que ele faça o tratamento direitinho, porque sei que não vou pegar sendo amigo dele (U6).

U4 disse que o dia tinha sido produtivo, que tinha aprendido mais e que iria repassar para os outros colegas que não tiveram a oportunidade.

Evidenciou-se que abordar a temática HIV/Aids para os jovens é muito complexo, principalmente porque é assunto sobre a intimidade deles. No entanto, procurou-se utilizar de estratégias dinâmicas e lúdicas, se aproximando da realidade deles, para que se sentissem à vontade e participassem de forma espontânea, sem medos e vergonhas dos companheiros, para que ao final todos construíssem conhecimentos de forma coletiva.

\section{$3^{\circ}$ Círculo de Cultura - 0 que aprendemos sobre Aids?}

Para consolidar o conhecimento acerca do HIV/Aids, pensou-se em uma atividade lúdica que permitisse aos participantes socializar o conhecimento apreendido nos Círculos anteriores.

No primeiro momento, sugeriu-se que, individualmente, desenhassem ou recortassem das revistas, imagens que retratassem para eles as DST/Aids e após esta etapa, cada um iria explicar a sua escolha.Assim, foram disponibilizados: papéis, colas, tesouras, revistas, lápis de cor e canetinhas. Após estipular o tempo para execução da atividade que durou aproximadamente 20 minutos, cada jovem colou o seu desenho ou gravura em um grande painel, cujo resultado final foi a elaboração do painel intitulado: o que representa para vocês às DST/Aids?
Nos desenhos/gravuras selecionados, os jovens procuraram retratar não somente o que aprenderam sobre as DST/Aids, como também a questão das drogas como facilitadora da contaminação pelo HIV, pois estava intrinsecamente relacionada a vida deles.

No momento de exposição dos desenhos, o primeiro a terminar e colar o desenho no quadro foi U7, e o descreveu assim:

Esta é uma mulher fumando um cigarro, a outra é uma figura de uma caipirinha que tem álcool, aí a pessoa quando bebe não sabe o que fazer, aí acaba fazendo besteira, porque ela está aqui nesta outra figura de uma festa, e depois o sexo sempre vem à tona, e as DST/Aids se encontram neste contexto (U7).

Eu colei três figuras, um casal fazendo sexo, depois um monte de tubinhos com sangue, que representa o teste do HIV que a pessoa que faz sexo sem preservativo deve fazer, e a terceira figura são vários corpos mortos, que é o resultado daquelas pessoas que não fazem o tratamento (U2).

Eu colei a foto de um casal, e outra de um drink, e escrevi assim: como é fácil adquirir DST e Aids. Estão um casal namorando e depois eles foram beber, porque a bebida esquenta tudo, e com certeza o sexo vem logo depois. $E$ 99\% deles não se protegem com camisinha e aí é que eles conseguem adquirir e transmitir DST e Aids (U5).

O grupo discorreu muito sobre a questão do uso do preservativo, enfocando somente a relação sexual como meio de se contaminar com o HIV; a questão do parceiro único; também referiu a Aids como doença que deve ser feito o exame para diagnóstico, podendo ser mortal se não for tratada; e o uso de drogas, no caso a bebida, como facilitadora de atos irresponsáveis e de não uso do preservativo.

Para este segundo momento, exibiu-se o vídeo Rep da Prevenção, que retrata através da música a importância da adoção de atitudes seguras frente às DST. Este vídeo serviu de aprendizado e inspiração para que eles pudessem realizar a atividade de construção de uma música, um poema ou uma paródia sobre prevenção das DST/Aids em usuários de drogas.

Estudo com meninos de rua também utilizou esse vídeo Rep da Prevenção, o qual foi bastante elogiado pelos adolescentes por causar neles muitos questionamentos e diálogos produtivos ${ }^{14}$.

Nessa perspectiva, o grupo dividiu-se por afinidade, formando quatro equipes, duas com três participantes e duas com dois participantes. Foi concedido 40 minutos para execução da atividade. Nesse momento, a animadora tinha o papel de observadora, somente intervindo quando solicitada. Os grupos estavam bastante animados e concentrados na atividade.

Logo após a redação das paródias e rep, os participantes apresentaram o texto, constituindo momento de alegria e descontração, e um retorno aos momentos anteriores de aprendizagem. 


\section{Grupo 1 - Paródia}

Aids te pego sem camisinha, Aids te pego gatinha, Na balada, umas biritas, sair, praticar sexo seguro, Aids te pego sem camisinha, Aids te pego gatinha, (Paródia da música "Ai se eu te pego", de autoria de Michel Teló).

O Grupo 1 escolheu uma música sertaneja para realizar esta paródia. Esse ritmo tem sido um dos mais escutados no Estado do Ceará, caracterizando-se como importante questão cultural. A paródia elaborada pelos jovens tinha como embasamento um chamado para a reflexão acerca das festas e da facilidade do sexo sem camisinha após uma "biritas".

\section{Grupo 2 - Rep 1}

Meu amigo ouça o que eu vou lhe falar, DST é uma doença fácil de evitar, É só usar a camisinha que você não vai pegar, Se você não usar, mal você vai ficar, Mas procure o tratamento para mais rápido se curar, Se você não procurar a morte te encontrará.

O grupo escolheu o ritmo do rep mostrado no vídeo. Fizeram durante a apresentação até os efeitos do som do rep na boca, tornando a apresentação divertida e muito dinâmica. Nesses trechos no rep, retrataram o conselho e a advertência que dariam a um amigo para que o mesmo não pegasse as DST, orientando a usar a camisinha, e se a pessoa não quiser usar, deveria procurar o serviço de saúde para saber se tinha a doença e em seguida realizar o tratamento.

\section{Grupo 3 - Rep 2}

DST são as doenças que vamos comentar, Nesse pequeno rep que vamos cantar, Primeiro passo é se diagnosticar, E indo ao posto de saúde para o exame começar, Desse jeito tudo vai melhorar, E a saúde você encontrará, Mas se você não se cuidar, Mal você vai ficar, 1234, Também eu vou rimar sobre as drogas, Drogas aqui e drogas nas escolas, Isso não dá certo, isso é ilusão, Tudo começa com uma simples curtição, Não se iluda meu amigo, Não se iluda meu irmão, Drogas é uma trágica ilusão, Nunca use drogas, que tudo vai dar certo, Procure à Jesus seu amigo concreto.

Nos trechos da apresentação, é possível perceber a riqueza dos detalhes que foi discutida durante os Círculos, em que verifica a prevenção, a procura pelo diagnóstico e importância do tratamento. Outro ponto muito bem abordado foi o apelo do rep para as drogas, alerta para aqueles que ainda estão nas escolas e não provaram das drogas, para que não se cedam aos apelos do uso.

\section{Grupo 4 - Rep 3}

Vamos apresentar formas simples e seguras de praticar o sexo e viver sua vida sexual sem DST e Aids, portanto você não pode ficar desinformado. Agora fique atento a alguns sintomas de DST: Corrimento, dor e ardência ao urinar, Dor nas relações sexuais, coceiras, Ardência nos órgãos genitais, verrugas, Agora vamos ver como se pega Aids: Nas relações sexuais, vaginais e anais sem proteção, Por objetos contaminados, como agulhas, Nas transfusões de sangue contaminado.

A dupla focou o rep nos principais sinais e sintomas das DST e nas diferentes formas de contaminação do vírus HIV. Isto vem a complementar o que os outros grupos ainda não tinham falado ou cantado, mostrando assim as diferentes visões e aprendizados que cada um fez do mesmo assunto.

Por meio das atividades propostas durante este Círculo, os jovens demonstraram a segurança do conhecimento sobre o sexo seguro através das músicas criadas e cantadas, revelando a necessidade do uso do preservativo como meio de prevenção das DST/Aids e também que o parceiro único complementa essa relação sexual de forma mais protegida.

Diante dessas ações criativas e reflexivas, deve-se pensar na realização de pesquisas com participação ativa dos sujeitos, utilizando estratégias pedagógicas de enfermagem, que potencializem a investigação, bem como a implementação de orientações para o bem-estar humano por meio de técnicas e métodos diferentes.

Estudo com adolescentes demonstrou uma ação educativa que teve a dança e/ou música como mediadora na abordagem de assuntos de interesses dos jovens, como: sexualidade, puberdade, prevenção de DST e HIV, permitindo assim que redescobrissem a percepção do risco e da vulnerabilidade que se encontravam ${ }^{18}$.

Importante compreender que "a educação é uma forma de cuidar e o cuidado é uma forma de educar"19. Assim, a educação que potencializa o cuidar deve estar incorporada à prática da enfermagem, pautada em prol da melhor qualidade de vida.

\section{CONCLUSÃO}

Os Círculos de Cultura como estratégia para problematização e reflexão de aspectos vivenciados pelos jovens usuários de drogas no âmbito da prevenção das DST/HIV/Aids permitiu desvelar aspectos próprios da experiência desses indivíduos, agregando outros conhecimentos a partir da cultura do grupo. Nesse espaço, foram estimulados aspectos da criatividade, do lúdico, da comunicação, do vínculo, do diálogo e da escuta.

$\mathrm{Na}$ vivência, ver-se a desconstrução de conceitos referentes ao HIV/Aids, formas de transmissão e prevenção, inicialmente limitada apenas ao uso de preservativo e a ausência de articulação com os riscos decorrentes do uso de drogas e, a reconstrução de conhecimentos pela incorporação de novos elementos tendo como arcabouço as experiências pessoais e a relação compartilhada entre os participantes.

Estas práticas devem ser valorizadas em outros espaços de modo a reforçar a adoção de comportamentos saudáveis 
que repercutam na qualidade de vida e no alcance de ações preventivas frente aos riscos e vulnerabilidades que estes indivíduos estão sujeitos, tendo o enfermeiro um importante parceiro no alcance destas práticas.

É importante destacar as limitações do estudo, a saber: os jovens não possuírem em seu processo contínuo de tratamento práticas reflexivas que os levassem a adotar uma postura proativa durante as ações desenvolvidas, e a falta de continuidade das atividades educativas com a finalidade de favorecer um processo de recuperação desses sujeitos.

Ressalta-se, a necessidade de realização de outros estudos com uma amostra mais representativa e que utilizem instrumentos que possibilitem a avaliação do Círculo de Cultura como estratégia metodológica que favoreça a construção de espaço crítico-reflexivo acerca da prevenção do HIV/Aids entre jovens usuários de crack.

\section{REFERÊNCIAS}

1. WHO, World Health Organization. Young People's Health a Challenge for Society. Report of a WHO Study Group on Young People and Health for All. Technical Report Series 731. Geneva: WHO, 1986.

2. Conselho Nacional de Juventude (BR). Estatuto da Juventude. Lei $n^{\circ} 12.852$, de 5 de agosto de 2013. Organização Internacional do Trabalho (OIT) [Internet]. [acesso 2014 Jan 22]. Disponível em: http://juventude.gov.br/articles/ participatorio/0005/9412/Estatuto_de_Bolso_Web.pdf

3. Silva MAI, Mello FCM, Mello DF, Ferriani MGC, Sampaio JMC, Oliveira WA. Vulnerabilidade na saúde do adolescente: questões contemporâneas. Ciência \& Saúde coletiva. 2014; 19(2): 619-37.

4. Coelho MMF, Torres RAM, Miranda KCL, Cabral RL, Almeida LKG, Queiroz MVO. Educação em saúde com adolescentes: compartilhando vivências e reflexões. Cienc Cuid Saude. 2012 Abr/Jun; 11(2): 390-395.

5. Ferreira AGN, Vieira NFC, Transferetti JA, Galvão MTG, Gubert FA, Pinheiro PNC. Dialogando com adolescentes de grupos religiosos sobre hiv: desafios para a enfermagem.Texto Contexto Enferm [Internet]. 2013; 22(4): 952-60. [acesso 2014 Jan 23]. Disponível em: http://www.scielo.br/scielo. php?script=sci_arttext \&pid=S0104-07072013000400011.

6. Araújo TME, Sousa AS, Soares TR, Clementino RA, Sá LC, Lima SM. Vulnerabilidade dos usuários de crack à infecção pelo vírus da imunodeficiência humana. Enferm. Foco. 2014; 5(1/2): 45-48.

7. Fonseca FF, Sena RKR, Santos RLA, Dias OV, Costa SM. As vulnerabilidades na infância e adolescência e as políticas. Rev Paul Pediatr. 2013; 31(2): 258-64.

8. Thiollent M. Metodologia da pesquisa-ação. 18a ed. São Paulo: Cortez; 2011.

9. Brandão CR. O que é método Paulo Freire. 32. ed. São Paulo: Brasiliense, 2011.

10. Minayo MC. O Desafio do Conhecimento: pesquisa qualitativa em saúde. 12a ed. São Paulo (SP): HUCITEC; 2010.

11. Brasil. Conselho Nacional de Saúde. Resolução 466/12. Diário Oficial União, 2013 jun.12, Seção 1 - p. 59. [acesso
2012 Jun 10]. Disponível em: http://conselho.saude.gov.br/ resolucoes/2012/Reso466.pdf.

12. Barbosa MR, Matos, PM, Costa ME. As Relações de Vinculação e a Imagem Corporal: Exploração de um Modelo. Psicologia: Teoria e Pesquisa. 2011; 27(3): 273-282.

13. Moura ADA, Oliveira RMS, Lima GG, Farias LM, Feitoza AR. O comportamento de prostitutas em tempos de aids e outras doenças sexualmente transmissíveis: como estão se prevenindo? Texto Contexto Enferm. 2010; 19(3): 545-53.

14. Luna IT, Costa AGM, Costa MS, Alves MDS, Vieira NFC, Pinheiro PNC. Conhecimento e prevenção das doenças sexualmente transmissíveis entre os adolescentes em situação de rua. Ciência, Cuidado e Saúde [Internet]. 2013; 12(1): 346-355. [acesso 2014 Fev 13]. Disponível em: http://www.periodicos. uem.br/ojs/index.php/CiencCuidSaude/article/view/18693.

15. Brêtas JRS, Ohara CVS, Jardim DP, Muroya, RL. Conhecimento sobre DST/AIDS por adolescentes. Rev Esc Enferm USP. 2009; 43(3): 551-7.

16. Sousa LB, Leitão NMA, Pinheiro AKB, Pereira MLD, Barbosa RCM, Silva MAM. Desenvolvimento de tecnologia educativa para prevenir DST/HIV/aids a partir da teoria de Madeleine Leininger. Revista de Enfermagem da UFPI. 2013; 2(3):88-92.

17. Barbosa SM, Dias FLA, Pinheiro AKB, Pinheiro PNC, Vieira NFC. Jogo educativo como estratégia de educação em saúde para adolescentes na prevenção às DST. Rev Eletr Enf. 2010; 12(2): 337-341. [acesso 2012 Mar 24]. Disponível em: http:// dx.doi.org/10.5216/ree.v12i2.6710.

18. Costa AGM, Vieira NFC. Estratégia de Promoção da Saúde pela Dança (EPSD) com adolescentes. Revista Brasileira de Educação Física, Esporte, Lazer e Dança. 2009; 4(2):62-74.

19. Ramos FRS. et al. Trabalho, educação e política em seus nexos na produção bibliográfica sobre o cuidado. Texto Contexto Enferm. 2009; 18(2): 361-368. 